\title{
Cross-Sectional Study of Ethnicity and Chronic Heart Failure: Complex Interplay of Health and Wealth
}

\author{
Authors: \\ Hafisyatul Aiza Zainal Abidin, *Raja Ezman Raja Shariff, Sazzli Kasim \\ Cardiology Unit, Faculty of Medicine, Universiti Teknologi MARA (UiTM), Shah Alam, \\ Malaysia \\ *Correspondence to rajaezman@gmail.com \\ Disclosure: The authors have declared no conflicts of interest. \\ Received: $\quad 26.12 .2018$ \\ Accepted: $\quad 03.01 .2020$ \\ Keywords: $\quad$ Cardiomyopathy, epidemiology, heart failure. \\ Citation: $\quad$ EMJ. 2020;DOI/10.33590/emj/18-00121
}

\begin{abstract}
Objectives: Extrapolating data from international and regional registries on chronic heart failure provides a challenge in Malaysia in view of it being a multicultural country. This study aimed to illustrate the chronic heart failure landscape within northern Kuala Lumpur and identify differences amongst major ethnic groups.
\end{abstract}

Methods: A retrospective, single-centre study was conducted between the $1^{\text {st }}$ January 2013 and $30^{\text {th }}$ April 2016. Patients with left ventricular ejection fraction $\leq 45 \%$ were identified and information was collected on these individuals' demographics, risk factors, and aetiology. Comparisons were made between three major ethnic groups within Malaysia, and between the author's database and that of other international registries.

Results: 1,181 patients were identified, the majority being Malay (67.3\%) and male (81.2\%). The mean age was $58.6 \pm 11.4$ years. The majority had ischaemic risk factors, including previous and current smoking habits (56.7\%), coronary artery disease (61.5\%), hypertension (66.6\%), diabetes (57.7\%), and dyslipidaemia (44.5\%). There were significant differences noted when looking at rates of dyslipidaemia, diabetes, atrial fibrillation, and chronic kidney disease amongst different ethnicities. The mean left

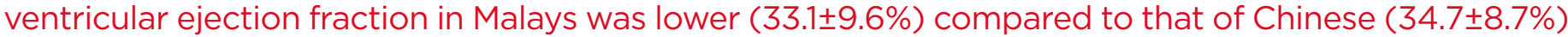

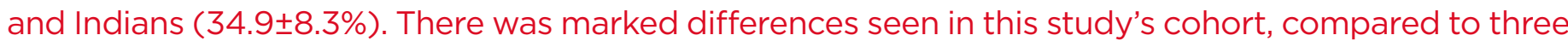
major Asian registries: The 2003 Chong et al. registry, Inter-CHF, and ASIAN-HF.

Conclusion: There exists great disparity in chronic heart failure burden amongst populations, and therefore local registries are needed to narrow the gap in knowledge regarding chronic heart failure within Malaysia.

\section{INTRODUCTION}

Heart failure affects up to 26 million adults worldwide.' The overall economic cost of heart failure in 2012 was estimated to be $\$ 108$ billion

per annum in the USA, of which $60 \%$ was related to inpatient care. ${ }^{2,3}$ There has been increasing awareness over the last decade of the importance of developing heart failure registries to better understand the burden of the disease. 
Unfortunately, the majority of these registries are focussed on Western populations. ${ }^{4,5}$ With a population of over 600 million people within South East Asia, where the ethnicity and healthcare services are diverse, extrapolating data from pre-existing registries may not be appropriate, and there is a need for a dataset that reflects the impact of disease on the Malaysian population, specifically on various ethnic groups. Only a few collaborative international registries exist (e.g., ADHERE-AP, 2011; ASIAN-HF, 2016; Inter-CHF, 2016), which include 1,808 patients from Malaysia accumulatively: a gross under-representation of the Malaysian population as a whole. ${ }^{6-8}$ This study aimed to illustrate the variation in chronic heart failure landscape within northern Kuala Lumpur and identify differences amongst the major ethnic groups in Malaysia. This study's dataset was compared with that of other Asian registries.

Heart Failure is a major burden in the majority of countries and registries allow us to better understand the affected populations. Differences in heart failure progression amongst various ethnic groups exist and yet are poorly documented. The multicultural landscape of Malaysia provides a foundation in which we can better understand the influence of socioeconomic factors in heart failure prognosis and outcomes. Understanding socioeconomic factors allows for better tailoring of disease management, as opposed to adopting a 'one size fits all' strategy in our population.

\section{METHODS}

A retrospective, single-centre study was conducted by reviewing all echocardiography reports available in the Cardiology Unit at the Universiti Teknologi MARA (UiTM) between the $1^{\text {st }}$ January 2013 and 30 ${ }^{\text {th }}$ April 2016. The centre is a university-linked hospital with in-house cardiology services, offering both invasive and noninvasive treatments. Referrals are primarily from primary care and other hospitals, usually within the northern Kuala Lumpur region. Information on medication and prior investigations or interventions performed were not necessarily available unless provided by the referring centres. The cardiology unit consists of a team of cardiology consultants, registrars, and nursing professionals with training in cardiology care. Echocardiography is performed by both clinicians and cardiovascular scientists with recognised, in-house training. Services are audited annually to ensure quality assurance. External sources of echocardiography results were excluded from this study. The possibility of systematic difference would be kept minimal as training provided inhouse reflects that of national standards.

Patients with a recorded left ventricular ejection fraction (LVEF) of $\leq 45 \%$, with clinical symptomsand signs consistent with heart failure as determined by clinicians, were included in the study. Patients were contacted prior to data collection to allow for accurate data capture on mortality. Information on demographics, cardiovascular risk factors, and aetiology of heart failure were obtained from the corresponding electronic medical record. Data analysis was performed via IBM SPSS statistical software version $23.0^{\circ}$ (Armonk, New York, USA), and comparison was made between the three major ethnic groups in Malaysia: Malay, Chinese, and Indian. Further analysis was performed by comparing results with that of other established registries. Descriptive statistics were used to summarise patient characteristics and other variables. Categorical data were presented by frequency and percentage. Continuous data were analysed using mean and standard deviation. Comparisons across different ethnic groups were analysed via chi square and ANOVA testing. Institutional ethics committee approval was obtained from the university, and no financial support was necessary for this study.

\section{RESULTS}

\section{Comparison Between Ethnic Groups}

An all-inclusive total of 1,181 patients with LVEF $\leq 45 \%$ were identified between the $1^{\text {st }}$ January 2013 and 30 th April 2016 (Table 1). The majority of patients were Malay (67.3\%) and male (81.2\%). When divided into different ethnic groups, male predominance was also seen (Table 1). The mean age was $58.6 \pm 11.4$ years old. It was noted that Indians tended to experience heart failure at a younger age ( $57.8 \pm 0.4$ years). Of note, more than half of patients in each ethnic group were aged 50-69 years old.

Slightly more than half $(56.7 \%)$ of patients were smokers or ex-smokers, and the majority exhibited common ischaemic risk factors, including coronary artery disease (61.5\%), hypertension (66.6\%), diabetes (57.7\%), and dyslipidaemia (44.5\%). 
Table 1: Baseline characteristics of chronic heart failure in north Kuala Lumpur.

\begin{tabular}{|c|c|c|c|c|c|c|}
\hline & Total & Malay & Chinese & Indian & Other & p value \\
\hline & $(\mathrm{N}=1,181)$ & $(n=795)$ & $(n=204)$ & $(n=168)$ & $(n=14)$ & \\
\hline Male & $81.2 \%$ & $80.7 \%$ & $84.3 \%$ & $81.1 \%$ & $69.2 \%$ & \\
\hline \multicolumn{7}{|c|}{ Age } \\
\hline Mean age & $58.6 \pm 11.4$ & $58.2 \pm 11.7$ & $62.0 \pm 10.0$ & $57.8 \pm 0.4$ & $46.1 \pm 14.2$ & $p<0.001$ \\
\hline$<40$ & $65(5.5 \%)$ & $49(6.2 \%)$ & $4(2.0 \%)$ & $7(4.2 \%)$ & $5(35.7 \%)$ & \\
\hline $40-49$ & $176(14.9 \%)$ & $125(15.7 \%)$ & $22(10.8 \%)$ & $26(15.5 \%)$ & $3(21.4 \%)$ & \\
\hline $50-59$ & 359 (30.4\%) & $244(30.7 \%)$ & $52(25.5 \%)$ & $59(35.1 \%)$ & $4(28.6 \%)$ & \\
\hline $60-69$ & $386(32.7 \%)$ & 245 (30.8\%) & $81(39.7 \%)$ & $59(35.1 \%)$ & $1(7.1 \%)$ & \\
\hline $70-79$ & $168(14.2 \%)$ & $112(14.1 \%)$ & 39 (19.1\%) & $16(9.5 \%)$ & $1(7.1 \%)$ & \\
\hline$>80$ & $27(2.3 \%)$ & $20(2.5 \%)$ & $6(2.9 \%)$ & $1(0.6 \%)$ & $0(0.0 \%)$ & \\
\hline Heart rate (bpm) & $74.0 \pm 14.0$ & $74.8 \pm 15.0$ & $72.6 \pm 13.7$ & $76.6 \pm 15.0$ & $80.9 \pm 15.6$ & $p<0.05$ \\
\hline \multicolumn{7}{|c|}{ Blood pressure $(\mathrm{mmHg})$} \\
\hline Systolic & $128 \pm 22$ & $129 \pm 23$ & $125 \pm 20$ & $124 \pm 19$ & $125 \pm 24$ & $p>0.05$ \\
\hline Diastolic & $76 \pm 14$ & $77 \pm 14$ & $74 \pm 13$ & $74 \pm 13$ & $77 \pm 14$ & $p>0.05$ \\
\hline \multicolumn{7}{|c|}{ Smoking status } \\
\hline Smoker & $228(19.3 \%)$ & $145(18.2 \%)$ & $49(24.0 \%)$ & $33(19.6 \%)$ & $1(7.1 \%)$ & \\
\hline Ex-smoker & $349(29.6 \%)$ & $251(31.6 \%)$ & $46(22.5 \%)$ & $50(29.8 \%)$ & $2(14.3 \%)$ & \\
\hline \multicolumn{7}{|c|}{ Medical history } \\
\hline CAD & $726(61.5 \%)$ & $475(59.7 \%)$ & $124(60.8 \%)$ & $118(70.2 \%)$ & $9(64.3 \%)$ & $p>0.05$ \\
\hline Hypertension & $786(66.6 \%)$ & $527(66.3 \%)$ & $131(64.2 \%)$ & $122(72.6 \%)$ & $6(42.9 \%)$ & $p>0.05$ \\
\hline Diabetes & $681(57.7 \%)$ & $440(55.3 \%)$ & 109 (53.4\%) & $128(76.2 \%)$ & $4(28.6 \%)$ & $p<0.0001$ \\
\hline Dyslipidaemia & $526(44.5 \%)$ & $363(45.7 \%)$ & $77(37.7 \%)$ & $83(49.4 \%)$ & $3(21.4 \%)$ & $p<0.05$ \\
\hline CKD & $163(13.8 \%)$ & $126(15.8 \%)$ & $26(12.7 \%)$ & $11(6.5 \%)$ & $0(0.0 \%)$ & $p<0.05$ \\
\hline Stroke & $78(6.6 \%)$ & $55(6.9 \%)$ & $14(6.9 \%)$ & $9(5.4 \%)$ & $0(0.0 \%)$ & $p>0.05$ \\
\hline Hyperthyroidism & $20(1.7 \%)$ & $14(1.8 \%)$ & $1(0.5 \%)$ & $4(2.4 \%)$ & $1(7.1 \%)$ & $p>0.05$ \\
\hline Atrial fibrillation & $86(7.3 \%)$ & $70(8.8 \%)$ & $11(5.4 \%)$ & $5(3.0 \%)$ & $0(0.0 \%)$ & $p<0.05$ \\
\hline COPD & $20(1.7 \%)$ & $12(1.5 \%)$ & $3(1.5 \%)$ & $4(2.4 \%)$ & $1(7.1 \%)$ & $p>0.05$ \\
\hline \multicolumn{7}{|c|}{ LVEF (\%) } \\
\hline Mean & & $33.1 \pm 9.6$ & $34.7 \pm 8.7$ & $34.9 \pm 8.3$ & $36.6 \pm 8.9$ & $\mathrm{p}<0.05$ \\
\hline $40-45$ & $419(35.5 \%)$ & $270(34.0 \%)$ & $81(39.7 \%)$ & $61(36.3 \%)$ & $8(57.1 \%)$ & $p>0.05$ \\
\hline $25-39$ & $553(46.8 \%)$ & 369 (46.4\%) & $96(47.1 \%)$ & $83(49.4 \%)$ & $5(35.7 \%)$ & $p>0.05$ \\
\hline$<25$ & $104(8.8 \%)$ & $154(19.4 \%)$ & $25(12.3 \%)$ & $24(14.3 \%)$ & $1(7.1 \%)$ & $p>0.05$ \\
\hline \multicolumn{7}{|c|}{ Aetiology } \\
\hline $\begin{array}{l}\text { Ischaemic heart } \\
\text { disease }\end{array}$ & $726(61.5 \%)$ & 475 (59.7\%) & 124 (60.8\%) & 118 (70.2\%) & $9(64.3 \%)$ & $p>0.05$ \\
\hline $\begin{array}{c}\text { Valvular heart } \\
\text { disease }\end{array}$ & 412 (34.9\%) & 290 (36.5\%) & 66 (32.4\%) & $50(29.8 \%)$ & $6(42.9 \%)$ & $p>0.05$ \\
\hline Cardiomyopathy & $39(3.3 \%)$ & $28(3.5 \%)$ & $7(3.4 \%)$ & $4(2.4 \%)$ & $0(0.0 \%)$ & $p>0.05$ \\
\hline Thyrotoxicosis & $20(1.7 \%)$ & $14(1.8 \%)$ & $1(0.5 \%)$ & $4(2.4 \%)$ & $1(7.1 \%)$ & $p>0.05$ \\
\hline Arrhythmias & $39(3.3 \%)$ & $34(4.3 \%)$ & $5(2.5 \%)$ & $0(0.0 \%)$ & $0(0.0 \%)$ & $p>0.05$ \\
\hline
\end{tabular}

bpm: beats per minute; CAD: coronary artery disease; CKD: chronic kidney disease; COPD: chronic obstructive pulmonary disease; LVEF: left ventricular ejection fraction. 
Table 2: Demographic comparison with other Asian based registries.

\begin{tabular}{|c|c|c|c|c|}
\hline & North Kuala Lumpur & Chong et al. ${ }^{9}$ & ASIAN-HF & Inter-CHF \\
\hline & Heart Failure Registry & 2003 & 2016 & (Asia) \\
\hline & 2017 & $(N=97)$ & & 2016 \\
\hline & $(N=1,181)$ & & $(N=5,276)$ & $(N=1,253)$ \\
\hline Male & $81.2 \%$ & $80.7 \%$ & $78.2 \%$ & $69.0 \%$ \\
\hline Mean age & 58.6 & 53.6 & 59.6 & 58.5 \\
\hline \multicolumn{5}{|c|}{ Blood pressure $(\mathrm{mmHg})$} \\
\hline Systolic & $128 \pm 22$ & $\mathrm{~N} / \mathrm{A}$ & $118.4 \pm 20.2$ & $\mathrm{~N} / \mathrm{A}$ \\
\hline Diastolic & $76 \pm 14$ & $\mathrm{~N} / \mathrm{A}$ & $72.4 \pm 12.6$ & $\mathrm{~N} / \mathrm{A}$ \\
\hline \multicolumn{5}{|c|}{ Smoking status } \\
\hline Smoker/ex-smoker & $56.7 \%$ & $22.7 \%$ & $45.0 \%$ & $35.9 \%$ \\
\hline \multicolumn{5}{|c|}{ Medical history } \\
\hline CAD & $61.5 \%$ & $49.5 \%$ & $50.2 \%$ & $26.3 \%$ \\
\hline Hypertension & $66.6 \%$ & $49.5 \%$ & $51.9 \%$ & $55.3 \%$ \\
\hline Diabetes & $57.7 \%$ & $28.9 \%$ & $40.4 \%$ & $32.7 \%$ \\
\hline Dyslipidaemia & $44.5 \%$ & $\mathrm{~N} / \mathrm{A}$ & $\mathrm{N} / \mathrm{A}$ & $25.1 \%$ \\
\hline CKD & $13.8 \%$ & $\mathrm{~N} / \mathrm{A}$ & N/A & $8.23 \%$ \\
\hline Stroke & $6.6 \%$ & $\mathrm{~N} / \mathrm{A}$ & $6.4 \%$ & $4.37 \%$ \\
\hline Hyperthyroidism & $1.7 \%$ & $1.0 \%$ & N/A & $\mathrm{N} / \mathrm{A}$ \\
\hline Atrial fibrillation & $7.3 \%$ & $4.1 \%$ & $17.9 \%$ & $\mathrm{~N} / \mathrm{A}$ \\
\hline COPD & $1.7 \%$ & $12.4 \%$ & $8.3 \%$ & $\mathrm{~N} / \mathrm{A}$ \\
\hline Mean LVEF (\%) & $33.7 \pm 9.3$ & $\mathrm{~N} / \mathrm{A}$ & $28.0 \%$ & $\mathrm{~N} / \mathrm{A}$ \\
\hline \multicolumn{5}{|c|}{ Causes of heart failure } \\
\hline $\begin{array}{l}\text { Ischaemic heart } \\
\text { disease }\end{array}$ & $61.5 \%$ & $49.5 \%$ & $47.0 \%$ & $48.0 \%$ \\
\hline $\begin{array}{c}\text { Valvular heart } \\
\text { disease }\end{array}$ & $34.9 \%$ & $4.1 \%$ & N/A & $12.0 \%$ \\
\hline Cardiomyopathy & $3.3 \%$ & $4.1 \%$ & $\mathrm{~N} / \mathrm{A}$ & $11.0 \%$ \\
\hline Thyrotoxicosis & $1.7 \%$ & $1.0 \%$ & N/A & $5.0 \%$ \\
\hline Arrhythmias & $3.3 \%$ & $\mathrm{~N} / \mathrm{A}$ & $\mathrm{N} / \mathrm{A}$ & N/A \\
\hline Hypertension & N/A & $18.6 \%$ & N/A & $14.0 \%$ \\
\hline $\begin{array}{c}\text { Number } \\
\text { of patients from } \\
\text { Malaysia (n) }\end{array}$ & 1,181 & 97 & 541 & 362 \\
\hline
\end{tabular}

ASIAN-HF: Asian Sudden Cardiac Death in Heart Failure; CAD: coronary artery disease; CKD: chronic kidney disease; COPD: chronic obstructive pulmonary disease; Inter-CHF: International Congestive Heart Failure; LVEF: left ventricular ejection fraction; N/A: not available.

When comparisons were made between ethnic groups, there were significant differences in the rate of diabetes, for which Indians ranked highest (76.2\%), followed by Malays (55.3\%) and Chinese (53.4\%). The prevalence of atrial fibrillation (AF) in this cohort was low, at $7.3 \%$. When analysing individual ethnic groups, Malays presented more commonly with AF (8.8\%) as opposed to Chinese
(5.4\%) and Indians (3.0\%). The prevalence of chronic kidney disease was significantly higher in Malays (15.8\%) versus Chinese (12.7\%) and Indians (6.5\%). The majority of patients, as a whole (61.5\%) and within individual ethnic groups (59.7\%, $60.8 \%$, and $70.2 \%$ of Malays, Chinese, and Indians, respectively), presented with ischaemiarelated heart failure. 
Table 3: Comparison of major ethnicity in Malaysia versus ASIAN-HF cohort.

\begin{tabular}{|c|c|c|c|c|c|c|}
\hline & $\begin{array}{l}\text { Malay } \\
(n=795)\end{array}$ & $\begin{array}{l}\text { Malay* } \\
(n=810)\end{array}$ & $\begin{array}{l}\text { Chinese } \\
(n=204)\end{array}$ & $\begin{array}{l}\text { Chinese* } \\
(n=1,561)\end{array}$ & $\begin{array}{l}\text { Indian } \\
(n=168)\end{array}$ & $\begin{array}{l}\text { Indian* } \\
(n=1,649)\end{array}$ \\
\hline Male & $80.68 \%$ & $81.4 \%$ & $84.3 \%$ & $80.8 \%$ & $81.1 \%$ & $76.1 \%$ \\
\hline Mean age & $58.2 \pm 11.7$ & $56.4 \pm 11.4$ & $62.0 \pm 10.0$ & $60.8 \pm 13.5$ & $57.8 \pm 0.4$ & $58.1 \pm 12.2$ \\
\hline $\begin{array}{l}\text { Heart rate } \\
(\text { bpm) }\end{array}$ & $74.8 \pm 15.0$ & N/A & $72.6 \pm 13.7$ & $\mathrm{~N} / \mathrm{A}$ & $76.6 \pm 15.0$ & $\mathrm{~N} / \mathrm{A}$ \\
\hline \multicolumn{7}{|c|}{ Blood pressure $(\mathrm{mmHg})$} \\
\hline Systolic & $129 \pm 23$ & $121 \pm 21$ & $125 \pm 20$ & $120 \pm 20$ & $124 \pm 19$ & $116 \pm 19$ \\
\hline Diastolic & $77 \pm 14$ & $81 \pm 17$ & $74 \pm 13$ & $72 \pm 12$ & $74 \pm 13$ & $73 \pm 11$ \\
\hline \multicolumn{7}{|c|}{ Smoking status } \\
\hline $\begin{array}{l}\text { Smoker/ex- } \\
\text { smoker }\end{array}$ & $57.4 \%$ & $61.1 \%$ & $55.9 \%$ & $54.1 \%$ & $56.8 \%$ & $66.1 \%$ \\
\hline \multicolumn{7}{|c|}{ Medical history } \\
\hline CAD & $59.7 \%$ & $49.8 \%$ & $60.8 \%$ & $54.2 \%$ & $70.2 \%$ & $59.8 \%$ \\
\hline Hypertension & $66.3 \%$ & $62.1 \%$ & $64.2 \%$ & $57.5 \%$ & $72.6 \%$ & $42.5 \%$ \\
\hline Diabetes & $55.3 \%$ & $50.2 \%$ & $53.4 \%$ & $40.9 \%$ & $76.2 \%$ & $42.1 \%$ \\
\hline Stroke & $6.9 \%$ & $7.4 \%$ & $6.9 \%$ & $7.4 \%$ & $5.4 \%$ & $3.0 \%$ \\
\hline Atrial fibrillation & $8.8 \%$ & $14.1 \%$ & $5.4 \%$ & $23.1 \%$ & $3.0 \%$ & $4.7 \%$ \\
\hline COPD & $1.5 \%$ & $9.6 \%$ & $1.5 \%$ & $9.9 \%$ & $2.4 \%$ & $5.2 \%$ \\
\hline Mean LVEF (\%) & $33.1 \pm 9.6$ & $25.0 \pm 5.0$ & $34.7 \pm 8.7$ & $28.0 \pm 6.0$ & $34.9 \pm 8.3$ & $28.0 \pm 4.0$ \\
\hline \multicolumn{7}{|c|}{ Aetiology } \\
\hline $\begin{array}{c}\text { Ischaemic heart } \\
\text { Disease }\end{array}$ & $59.7 \%$ & $66.8 \%$ & $60.8 \%$ & $46.9 \%$ & $70.2 \%$ & $42.9 \%$ \\
\hline $\begin{array}{c}\text { Valvular heart } \\
\text { disease }\end{array}$ & $36.5 \%$ & N/A & $32.4 \%$ & N/A & $29.8 \%$ & N/A \\
\hline Cardiomyopathy & $3.5 \%$ & N/A & $3.4 \%$ & N/A & $2.4 \%$ & N/A \\
\hline Thyrotoxicosis & $1.8 \%$ & N/A & $0.5 \%$ & N/A & $2.4 \%$ & $\mathrm{~N} / \mathrm{A}$ \\
\hline Arrhythmias & $4.3 \%$ & N/A & $2.5 \%$ & N/A & $0.0 \%$ & N/A \\
\hline
\end{tabular}

*These data were taken from the Asian-HF registry.

ASIAN-HF: Asian Sudden Cardiac Death in Heart Failure; bpm: beats per minute; CAD: coronary artery disease; CKD: chronic kidney disease; COPD: chronic obstructive pulmonary disease; LVEF: left ventricular ejection fraction; N/A: not available.

The mean echocardiographic LVEF in Malays (33.1 $\pm 9.6 \%)$ was lower compared to that of

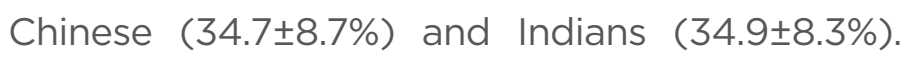
Systolic and diastolic blood pressure (129 \pm 23 , $125 \pm 20$, and $124 \pm 19 \mathrm{mmHg}$ in Malays, Chinese, and Indians, respectively; $p>0.05$ ) and average heart rate $(74.8 \pm 15,72.6 \pm 13.7$, and $76.6 \pm 15$ beats per minute in Malays, Chinese, and Indian, respectively; $p>0.05$ ) varied little across ethnicities. 


\section{Comparison Between Registries}

Comparison was made between this study's registry, and three others: Chong et al, ${ }^{9}$ Inter$\mathrm{CHF}^{8}$ and $\mathrm{ASIAN-HF},{ }^{7}$ with varying proportions of Malaysian patients being included in each (Table 2 and 3). There was a higher proportion of males in this study's cohort. The mean age of heart failure amongst the Malaysian population is comparable to other Asian-based registries, which is between 58 and 60 years of age., Interestingly, Chinese patients tend to be older in both this study's cohort and the Asian-HF registry.

Age of heart failure onset was at least a decade younger in this study's cohort versus European patients. ${ }^{4}$ This disparity may be due to the higher prevalence of physical inactivity, smoking, and obesity in this population which leads to the development of heart failure sooner as seen more commonly in youths. This is on top of pre-existing evidence of a higher prevalence of cardiovascular risk burden in Malaysia amongst other SouthEast Asian countries..$^{10-12}$ This is illustrated by this study's cohort, showing a higher prevalence of smoking (56.7\%), coronary artery disease (61.5\%), hypertension (66.6\%), diabetes (57.7\%), dyslipidaemia (44.5\%), chronic kidney disease (13.8\%), and stroke (6.6\%). Smoking was also seen to be less prevalent amongst Chinese patients compared to both Malays and Indians in this study, which may suggest not only an ethnicity component, but also environmental, cultural, and social elements linked to disease distribution.

The Malaysian prevalence of AF (7.3\%) was lower in comparison to the ASIAN-HF cohort. This study's findings are consistent with other Malaysianbased datasets, such as that of Lim et al.,13 in which overall prevalence of AF was $0.54 \%$, lower than the global average of $1.00 \% .^{13}$ Also noted was that this study's average LVEF was much lower $(33.7 \pm 9.3 \%)$ than compared with InterCHF (28.0\%), likely due to the heavy ischaemic burden noted in the Malaysian population which is greatly linked to heart failure with a reduced ejection fraction phenotype. ${ }^{14}$ When compared to the Inter-CHF group, despite lower left ventricular systolic function, mean systolic and diastolic blood pressure were roughly 10 and 5 $\mathrm{mmHg}$ higher, respectively, in this study's cohort. This is likely explained by a high prevalence of coexisting hypertension.

\section{DISCUSSION}

This is the largest reported heart failure population in Malaysia. It gives a unique perspective of the population in the north of Kuala Lumpur, with its multi-ethnic background. The distribution of patients within the sample population was comparable to that of Malaysia's demography, with a Malay population rate of $69.1 \%$, followed by 17.3\% Chinese and $14.2 \%$ Indian..$^{15}$

Income variation plays an important role is disease variance, as illustrated by the World Health Organization (WHO) Global Status Report 2014 revealing lower rates of physical inactivity, smoking, overweightness, impaired blood glucose, and raised blood pressure in highincome generating countries (such as the UK and USA, as well as Brunei and Singapore within the South-East Asian region). The converse is true for countries like Indonesia, Thailand, and Malaysia." Interestingly, income variation and disparity exist even between ethnic groups within a country, including that of Malaysia. Data support the fact that those of Chinese ethnicity generated the largest per capita income compared with those of Malay and Indian descent (1.49 versus 1.11 versus 1.24 , respectively)..$^{16}$ This may also partly explain the lower rates of smoking amongst Chinese in this study's cohorts, where an inverse relationship between income generation and tobacco use exist. ${ }^{17}$ Of note, due to a lack of data, the authors were unable to comment on differences in delivery of care, including medication prescription or monitoring of risk factors and heart failure progression, amongst different ethnic groups.

Research has shown the important role of ethnicity in disease outcome. Although genetic factors have been shown to be an important risk factor, the interdependency between socioeconomic characteristics, behavioural characteristics, and access to quality healthcare does exist and cannot be completely excluded. For example, the MESA, V-HeFT 1, and SOLVD trials found differences in cardiovascular burden and heart failure progression amongst different ethnic groups, based on differences in heart failure aetiology, neuro-hormonal pathway stimulation, and the pharmacological treatments administered..$^{18-20}$

It is important to discuss the burden of ischaemia, especially in the context of heart failure, as the majority (as seen in this study's cohort) of 
chronic heart failure cases are ischaemia driven (Table 1). Ethnicity-based disparities in cardiovascular risk factors and coronary artery disease have previously been reported by studies carried out in Singapore. 21,22 The young, male, and both Indian and Malay-predominant demographics in this study's population do not only mirror the existing demography of a Malaysian population as a whole, but also reflect the distribution of ischaemic heart disease burden within the population. The high proportion of patients with ischaemic risk factors, evidenced further by Malaysia's national ischaemic heart disease database, supports this. ${ }^{23}$ The male preponderance was expected, with established evidence highlighting ischaemia as being more prevalent in males and postmenopausal women. ${ }^{24}$ With regards to ethnic distribution, there is also evidence supporting a high proportion of ischaemia amongst Malays and Indians, as seen in both local (Zuhdi et al. ${ }^{25}$ and Hoo et al. ${ }^{26}$ ) and regional studies (Wong et al. ${ }^{27}$ ). Furthermore, studies have previously reported a higher prevalence of obesity and poor rate of engagement in physical activity amongst those of Malay and Indian descent. ${ }^{28}$

\section{Limitations}

Unfortunately, without information of the actual population within Malaysian locally and nationally, it is often difficult to interpret differences between ethnic groups and socioeconomic status. Furthermore, any differences in age, sex, and ethnicity might also be reflective of survivor bias, which is difficult to exclude in this study. However, this study's aim was to highlight the lack of such data and hopefully spur interest in collaborative efforts to develop local and national registries on chronic heart failure.

\section{Implications from the study}

This study highlights the uniqueness seen in a multi-ethnic population, which prior to this has not been demonstrated before. Although studies have been done in Malaysia's neighbouring country Singapore, results from those studies vary greatly and therefore are not extrapolatable to that of the Malaysian population, again illustrating the need for more local data on chronic heart failure. ${ }^{7}$ The data obtained will pave the way for establishing more regional and national registries to better understand the disease.

\section{CONCLUSION}

Registries are important to better understand the landscape of heart failure amongst populations. However, appreciation is needed for the great heterogeneity within populations that may or may not be best represented from an accumulative, large database such as that of Asian-HF or Inter-CHF. Even amongst neighbouring countries, for example Singapore and Malaysia, with a closely linked population demography because of historical and political factors, there exists a great disparity in disease burden and risk factors associated with disease development and progression. As the prevalence of heart failure increases, with an increase in survivorship amongst those affected by ischaemic cardiomyopathy, the development of local registries that take into account differences in cultural and economic factors are essential for future service development purposes.

\section{References}

1. Cook $\mathrm{C}$ et al. The annual global economic burden of heart failure. Int J Cardiol. 2014;171(3):368-76.

2. Stewart $\mathrm{S}$ et al. The current cost of heart failure to the National Health Service in the UK. Eur J Heart Fail. 2002;4(3):361-71.

3. Stewart $\mathrm{S}$ et al. More 'malignant' than cancer? Five-year survival following a first admission for heart failure. Eur $\mathrm{J}$ Heart Fail. 2001;3(3):315-22.

4. Nieminen MS et al. EuroHeart Failure Survey II (EHFS II): a survey on hospitalized acute heart failure patients: description of population. Eur Heart J. 2006;27(22):2725-36.

5. Fonarow GC et al. Temporal trends in clinical characteristics, treatments, and outcomes for heart failure hospitalizations, 2002 to 2004 : findings from Acute Decompensated Heart Failure National Registry (ADHERE). Am Heart J. 2007;153(6):1021-8.

6. Atherton $\mathrm{JJ}$ et al. Patient characteristics from a regional multicenter database of acute decompensated heart failure in Asia Pacific (ADHERE International-Asia Pacific). J Card Fail. 2012;18(1):82-8.

7. Lam CSP et al. Regional and ethnic differences among patients with heart failure in Asia: the Asian sudden cardiac death in heart failure registry. Eur Heart J. 2016;37(41):3141-53.

8. Dokainish $\mathrm{H}$ et al. Heart failure in Africa, Asia, the Middle East and South America: the INTER-CHF study. Int J Cardiol. 2016;204:133-41.

9. Chong $\mathrm{A}-\mathrm{Y}$ et al. Heart failure in 
a multiethnic population in Kuala Lumpur, Malaysia. Eur J heart Fail. 2003;5(4):569-74

10. Lear SA et al. The effect of physical activity on mortality and cardiovascular disease in 130000 people from 17 high-income, middle-income, and low-income countries: the PURE study. Lancet. 2017;390(10113):2643-54.

11. Lam CSP. Heart failure in Southeast Asia: facts and numbers. ESC Heart Fail. 2015;2(2):46-9.

12. Reyes EB et al. Heart failure across Asia: same healthcare burden but differences in organization of care. Int J Cardiol. 2016;223:163-7.

13. Lim CW et al. Prevalence of atrial fibrillation in the Malaysian communities. Heart Asia. 2016;8(2):62-6.

14. Lam CSP, Teng THK. Understanding heart failure with mid-range ejection fraction. JACC Heart Fail. 2016;4(6):473-6.

15. Department of Statistics of Malaysia. Current population estimates, Malaysia, 2017-2018. Available at: https://www.dosm. gov.my/v1/index.php?r=column/ cthemeByCat\&cat $=155 \&$ bul id=c1pqTnFjb29HSnNYNUpiTmNWZHArdzO9\&menu_id=LOpheU43N-
WJWRWVSZkIWdzQ4TIhUUT09. Last accessed: O2 Dec 2018.

16. Thomas $\mathrm{S}$ et al. Health care delivery in Malaysia: changes, challenges and champions. J Public Health Afr. 2011;2(2):e23.

17. Siahpush M et al. Racial/ethnic and socioeconomic variations in duration of smoking: results from 2003, 2006 and 2007 tobacco use supplement of the current population survey. J Public Health (Oxf). 2010;32(2):210-8.

18. Dries DL et al. Racial differences in the outcome of left ventricular dysfunction. N Engl J Med. 1999:340(8):609-16.

19. Carson P et al. Racial differences in response to therapy for heart failure: analysis of the vasodilatorheart failure trials. Vasodilator-Heart Failure Trial study group. J Card Fail. 1999:5(3):178-87.

20. Bahrami $\mathrm{H}$ et al. Differences in the incidence of congestive heart failure by ethnicity: the multi-ethnic study of atherosclerosis. Arch Intern Med. 2008;168(19):2138-45.

21. Lee $\mathrm{R}$ et al. Impact of race on morbidity and mortality in patients with congestive heart failure: a study of the multiracial population in Singapore. Int J Cardiol. 2009;134(3):422-5.
22. Hughes $\mathrm{K}$ et al. Cardiovascular diseases in Chinese, Malays, and Indians in Singapore. II. Differences in risk factor levels. J Epidemiol Community Health. 1990;44(1):29-35.

23. Wan Ahmad WA. Annual report of the NCVD-ACS registry, 2014 - 2015. Available at: https:// www.malaysianheart.org/ files/5d1998d5b6248.pdf. Last accessed: 08 January 2020.

24. Rosano GMC et al. Cardioprotective effects of ovarian hormones. Eur Heart J. 1996;17(Suppl D):15-9.

25. Zuhdi AS et al. Young coronary artery disease in patients undergoing percutaneous coronary intervention. Ann Saudi Med. 2013;33(6):572-8.

26. Hoo FK et al. Acute coronary syndrome in young adults from a Malaysian tertiary care centre. Pak J. Med Sci. 2016;32(4):841-5.

27. Wong CP et al. Acute myocardial infarction: clinical features and outcomes in young adults in Singapore. World J Cardiol. 2012;4(6):206-10.

28. Tan AKG et al. Ethnic disparities in metabolic syndrome in Malaysia: an analysis by risk factors. Metab Syndr Relat Disord. 2011;9(6):441-51. 